\title{
A COMPARATIVE STUDY OF THE PRIMARY VASCULAR SYSTEM OF CONIFERS. II. GENERA WITH OPPOSITE AND WHORLED PHYLLOTAXIS
}

\author{
Kadambari K. Namboodiri² and Charles B. Beck \\ Department of Botany, University of Michigan, Ann Arbor
}

A $\quad$ B $\quad \mathbf{S}$ T $\mathbf{R}$ A $\quad$ C $\mathbf{T}$

\begin{abstract}
This paper reports the results of a detailed comparative investigation of the primary vascular system of seven species of conifers characterized by opposite and whorled phyllotaxis. Three patterns, indicated as types I, II and III, are described. Type I is similar to the sympodial pattern of conifers with helical phyllotaxis. Type III is a reticulate system which results from a fusion of a pair of traces that form the vascular supply to each leaf. Each trace of the pair branches from a separate, adjacent sympodium, and the two traces diverge synchronously in opposite directions. Type II is intermediate between types I and III. It resembles type I in that the vascular supply to a leaf originates as a single trace, and it is similar to type III in that direction of trace divergence may be either sinistrorse or dextrorse. Four species were found to be characterized by both types II and III, the different types occurring in different shoot tips of the same individual. All three types were observed in one species. Where type II occurred in the same plant with either type I or type III, or in the one species in which all types occurred, some leaves were supplied by a trace originating singly, others by a trace originating as a pair of bundles. On the basis of a comparative analysis of the vascular patterns in conifers with helical, opposite and whorled phyllotaxis, including a correlation of the type of vascular pattern with other characters, it was concluded that the reticulate system is probably derived from the open system characteristic of conifers with helical leaf arrangement, that this type of vascular system is composed of sympodia, and that the origin of the vascular supply to a leaf as a single trace is the primitive condition in the Coniferales.
\end{abstract}

PART I of this study (Namboodiri and Beck, 1968) shows that in 23 genera of conifers with a helical phyllotaxis the primary vascular system consists of discrete, undulating vascular bundles from which leaf traces diverge singly in a regular pattern. For these observations to be of significance phylogenetically, we must be able to decide with confidence whether this type of vascular system is primitive or derived. Further evidence which bears on this important point is presented in this paper which records the results of a study of the vascular pattern of seven species of six genera belonging to three families of conifers with opposite and whorled leaf arrangement.

Geyler (1867) described two patterns of vasculature in conifers with these types of leaf arrangement: one, in forms with opposite leaves, very similar to the sympodial pattern characteristic of species with helically arranged leaves, and an anastomosing pattern in those species with whorled leaves. These patterns have been confirmed by deBary (1884), Barthelmess

${ }^{1}$ Received for publication 17 July 1967.

This paper is based on part of a Ph.D. thesis by the first author.

${ }^{2}$ Formerly known as G. Kadambari Kumari. Present address: Genetics Program, University of North Carolina, Chapel Hill, N.C. 27514.
(1935), Eames and MacDaniels (1947), and Camefort (1956). The vascular patterns of the groups investigated in the present study apparently represent three different categories. All three types have been encountered in plants with an opposite phyllotaxis as well as in those with whorled leaves. Sometimes these types, described below, are seen at different nodes in the same apex.

For a discussion of the techniques and terminology employed in this study, refer to Part I (Namboodiri and Beck, 1968).

Description-Type I-This pattern is very similar to the sympodial pattern found in species with helical phyllotaxis, the primary difference being the division of the axial bundles into leaf traces and new sympodial segments in relation to the opposite or whorled leaf arrangement. Figure 1 depicts the split-open vascular cylinder with the outer surface facing the observer. The leaves occur in an opposite and decussate arrangement, and there are four sympodia numbered at the bottom. Traces, one to each leaf, originate at intervals of two nodes from each sympodium. Alternate sympodia are synchronized in their division, giving rise to traces and new sympodial segments at the same level. Figures 2, 3 are transverse sections showing the 
insertions of leaves $1 \mathrm{a}$ and $1 \mathrm{~b}, 2 \mathrm{a}$ and $2 \mathrm{~b}$, and $3 \mathrm{a}$ and $3 b$, shown in Fig. 1. There are four vascular bundles in addition to the traces $2 \mathrm{a}$ and $2 \mathrm{~b}$ in Fig. 2. Of these the two diagonally placed sympodial segments $3 \mathrm{a}$ and $3 \mathrm{~b}$ divide, forming traces $3 \mathrm{a}$ and $3 \mathrm{~b}$ and new sympodial segments $5 \mathrm{a}$ and $5 \mathrm{~b}$, as illustrated in Fig. 3. It may also be noted that the direction of trace divergence is constantly sinistrorse.

Type II-This pattern is similar to Type I in that each leaf is supplied with a single trace, and as each bundle in the stem divides a trace and a new sympodial segment are formed. There is extreme irregularity, however, in the direction of trace divergence and in the number of intervening nodes between any two successive divisions of the same sympodium, as illustrated in Fig. 4-6. Figure 4 shows the outer perspective of the split-open vascular cylinder with its six sympodia numbered at the bottom. An examination of the first three sympodia will reveal the irregularities mentioned above. Traces diverge from sympodium II at three successive nodes and the direction of divergence of each trace is different from the preceding. Traces branch from sympodium I at intervals of two nodes, and sympodium III traverses several nodes without division. These same features can be observed in Fig. 5, 6 which illustrate the points of insertion of leaves at the first three nodes of the system shown in Fig. 4. Figure 5 shows sympodial segments $3 \mathrm{a}, 3 \mathrm{~b}$, and $3 \mathrm{c}$ which divide, giving rise at a higher level to traces $3 \mathrm{a}, 3 \mathrm{~b}$, and $3 \mathrm{c}$, and new sympodial segments. The divisions are shown in Fig. 6. ('Traces 3a, 3b, and 3c are shown cross-hatched.) It can be seen that the trace divergence of $3 \mathrm{c}$ is sinistrorse while that of $3 \mathrm{a}$ and $3 \mathrm{~b}$ is dextrorse.

Type III-The vascular system shows an anastomosing structure, but the general pattern of the division of a bundle in the stem that produces a trace and a sympodial segment found in the previous types is exactly the same. As in Type II the direction of trace divergence varies, but unlike II it regularly alternates at every node along the sympodium. It differs from Types I and II primarily in that two traces formed by the division of two neighboring sympodial segments fuse to form a single bundle that supplies a single leaf. Unlike the pattern in species with helical phyllotaxis (Namboodiri and Beck, 1968), in this type the leaf trace follows a tangential undulating course, and the newly formed sympodial segment generally maintains a straighter, more distinctly longitudinal position in the stem. Figures 7-9 summarize the pattern. Figure 7 represents diagrammatically the outer view of the spread-out vascular cylinder. Although it appears reticulate, the sympodial pattern found in the Types I and II is clearly discernible. The four sympodia are numbered at the bottom. Regularity in the alternation of trace divergence along a single sympodium, as well as the synchronized production of leaf traces between two neighboring sympodial segments and the fusion of the two traces, can be noted if any one of the four sympodia is traced upward. The retention, in the same position, of sympodial segments at successive nodes is illustrated in Fig. 8, 9. Segments $3 \mathrm{a}^{\prime}$ and $3 \mathrm{a}^{\prime \prime}$ (Fig. 8) divide and give rise to traces ( $\mathrm{Tr}$ ) that supply leaf $3 \mathrm{a}$ and new sympodial segments, $4 a^{\prime}$ and $4 b^{\prime}$ (Fig. 9). The sympodial segments, $4 a^{\prime}$ and $4 a^{\prime \prime}$ of Fig. 9, divide higher up and give rise to the two traces supplying leaf $4 a$ at the next higher node.

Table 1 summarizes the data on the vasculature and the distribution of the three types in the genera examined in this study.

Discussios-As the results presented in Table 1 clearly reveal, there is extreme irregularity in the vascular pattern and in the number of traces supplied to each leaf in conifers with opposite and whorled phyllotaxis. Even in the same plant some leaves are supplied with one and others with two traces. The vascular pattern Type II which exhibits differences in the direction of trace divergence is observed in several instances without any evidence of a corresponding change in phyllotaxis. In many cases vascular pattern Types II and III are observed in different parts of the same shoot apex. Sterling (1949) also found in Metasequoia two traces supplying some leaves and one in others. It may be argued that this irregularity is caused by the profuse production of axillary buds in these plants. But the relatively larger number of leaves which show differences in vascular supply as compared with the number of axillary buds suggests that the irregularity cannot be accounted for by the presence of axillary buds alone.

These data seem to suggest that extensive studies of this sort among conifer genera with opposite and whorled leaves may reveal more irregularities in the vascular pattern. How can one interpret the presence of such irregularities in the vasculature of the conifers with opposite and whorled leaf arrangement in view of the fact that those with helical phyllotaxis show a high degree of regularity (see Namboodiri and Beck, 1968)? Barthelmess (1935) suggested a probable reduction of the reticulate pattern to give rise to the sympodial pattern characteristic of genera with helical phyllotaxis (see his Fig. $29 a-d)$.

We suggest as an alternative hypothesis that the vasculature in species with helical phyllotaxis is basic and generalized and that of conifers with opposite and whorled phyllotaxis is derived. The hypothesis can be substantiated by strong circumstantial evidence. 


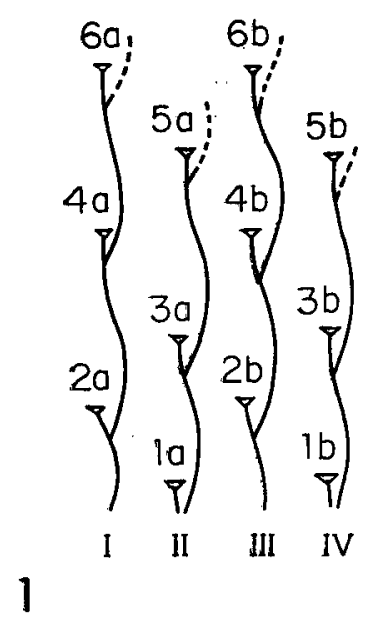

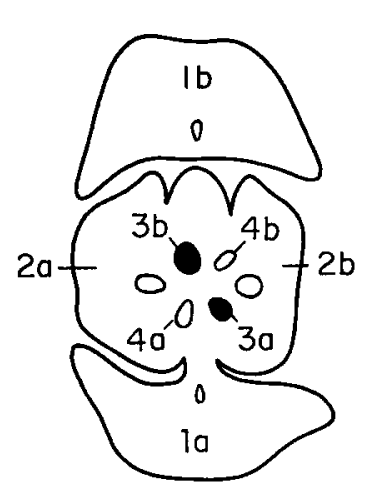

2

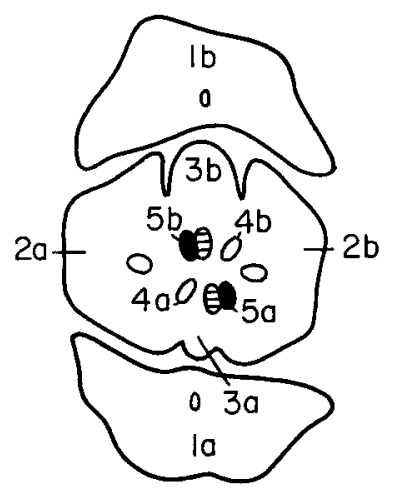

3

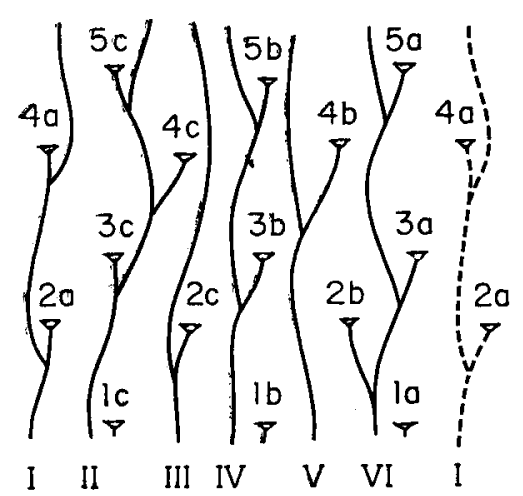

4

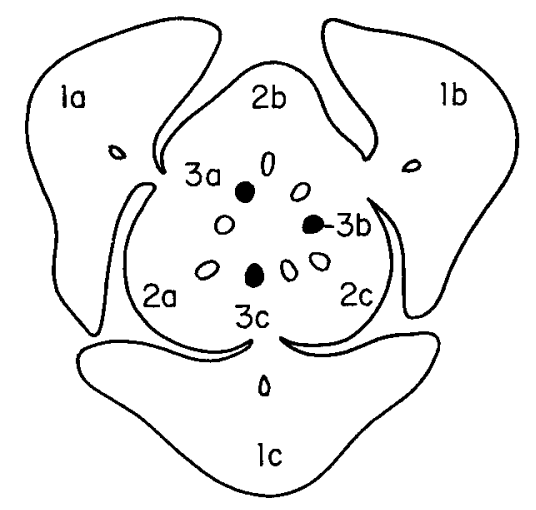

5

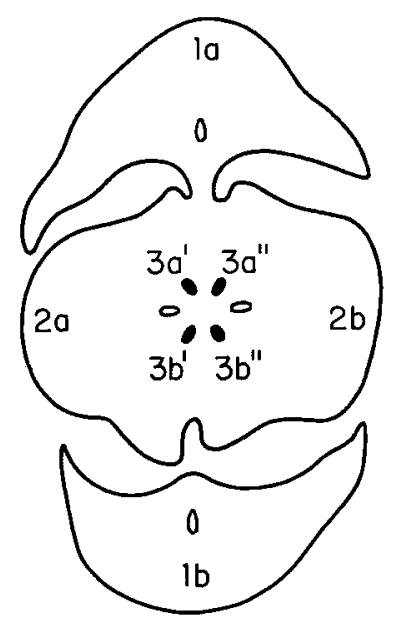

8
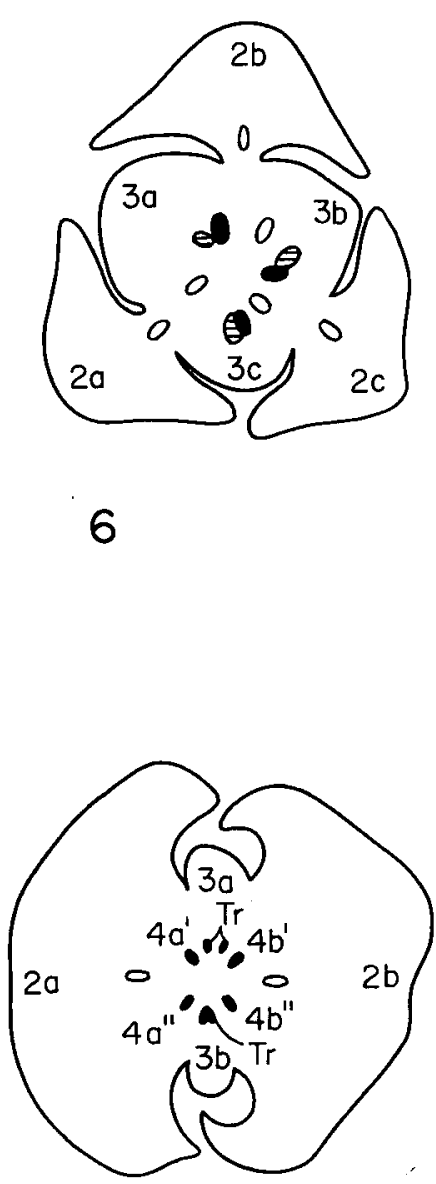

9 
The general occurrence of the sympodial pattern is evidence in support of this hypothesis. The sympodial pattern-that is, the production of a leaf trace and a continuing sympodial segment by the bifurcation of the preceding sympodial segment-seems to be characteristic of the majority of living conifers (Namboodiri and Beck, 1968). This feature is considered to be basic for the group because the attainment of such a common feature in different genera and families by parallel evolution is extremely implausible. While this pattern is accompanied by regularity in the direction of trace divergence in conifers with helical phyllotaxis, it is disrupted in many conifers with opposite and whorled leaves. The deviant pattern, hence, should be seen as diverging from the basic pattern observed in the forms with helical leaf arrangement rather than the converse.

Other evidence in support of the above hypothesis stems from the association of the regular sympodial pattern with helical phyllotaxis. There is ample evidence to show that this type of leaf arrangement is primitive and the opposite and whorled arrangement is derived. Florin (19381945 ; 1951) has presented strong evidence which suggests that the Cordaitales are the direct ancestors of conifers, and the Cordaitales show an undoubted helical arrangement of appendages. Further, in the fossil record there are very few instances of plants with oppositely arranged leaves, while there is an overwhelming record of plants with helically arranged leaves.

Opposite and whorled phyllotaxis are of rare occurrence among the living conifers (see Laubenfels, 1953). Apart from the Cupressaceae, where all the members possess opposite or whorled leaves, and the bijugate condition (actually a modification of the helical condition lacking orthostichies) previously noted in the Cephalotaxaceae, Taxaceae, etc., opposite leaf arrangement occurs in conifers only in the following: Agathis in the Araucariaceae, Meta- sequoia in the Taxodiaceae, and a small group of species of the genus Podocarpus of the Podocarpaceae (see Dallimore and Jackson, 1954). A correlation with other features indicates that there is no reason to regard these species as primitive. For example, Eames (1913), Aase (1915), and Florin (1951) have emphasized that the apparent simple condition of the female cone of Agathis results from the absolute coalesscence of the bract and the ovuliferous scale which is a well-recognized derived feature. Eames has said in connection with his comparative study of the group, that among the two genera, Araucaria and Agathis, the latter is "probably the more recent." Sterling, in a study of Metasequoia (1949), has considered the high degree of fusion between the bract and the ovuliferous scale, the dominance of the latter in the cone-scale unit, the opposite arrangement of the cone-scales and leaves, etc., as advanced features. In Podocarpaceae, likewise, the Nageia section of Podocarpus, characterized by opposite and sub-opposite leaves, is considered to be advanced. For example, Wilde (1944) studying the evolution of the female fruiting structures of Podocarpus suggests that the Nageia section is probably derived from primitive species like Podocarpus spicatus and Podocarpus andinus which have a helical arrangement of appendages. Thus based on a correlation of other features, the few genera in the families Araucariaceae, Taxodiaceae, and Podocarpaceae with opposite phyllotaxis seem to be derived rather than primitive. These may be regarded as rare deviants in families exhibiting a basic ground plan of helical phyllotaxis.

The Cupressaceae is usually considered by morphologists as an evolutionarily advanced group among the conifers. Its late appearance in the geological record (Arnold, 1947), the completely fused nature of the bract-scale units (Florin, 1951), the few prothallial cells in the male gametophyte (Chamberlain, 1935), and its em-

Fig. 1-9. Primary vascular structure of conifers with opposite and whorled leaves.-Fig. 1. A composite diagram of the outer perspective of the split-open vascular cylinder with vascular pattern Type I. Each of the four sympodia consists of an axial bundle from which leaf traces branch. The traces, which diverge in a regular manner, are numbered in sequence with those at the same node designated as a and b. Alternate sympodia are synchronized in their division, giving rise to traces and continuing sympodial segments at the same level.-Fig. 2, 3. Transverse sections of an apex showing vascular pattern Type $I$ as depicted in Fig. 1. Bundles 3a and $3 b$ of Fig. 2 divide and give rise sinistrorsely to traces (cross-hatched) seen in Fig. 3 and continuing sympodial segments $5 \mathrm{a}$ and $5 \mathrm{~b}$.-Fig. 4 . A composite diagram of the outer perspective of the split-open vascular cylinder with vascular pattern Type II. The six sympodia are numbered at the bottom. The traces are numbered in sequence with those belonging to leaves at the same node designated as a, b, and c. Traces are single, and the direction of trace divergence is irregular.-Fig. 5, 6. Transverse sections showing the same features depicted in Fig. 4. Sympodial segments $3 \mathrm{a}, 3 \mathrm{~b}$, and $3 \mathrm{c}$ (solid black) in Fig. 6 divide and give rise to traces (cross-hatched) and continuing sympodial segments (solid black) as seen in Fig. 6.-Fig. 7. A composite diagram of the outer perspective of the split-open vascular cylinder with vascular pattern Type III. The four sympodia are numbered at the bottom. The traces are numbered in sequence with those belonging to the leaves at the same node designated as $a$ and $b$. The reticulate appearance of the vascular system is due to the fusion of the two traces supplying each leaf. - Fig. 8, 9. Transverse sections showing the features depicted in Fig. 7. Each of the four bundles (solid black) in the stem divides at every node and each leaf is supplied with two traces. Bundles $3 \mathrm{a}^{\prime}, 3 \mathrm{a}^{\prime \prime}, 3 \mathrm{~b}^{\prime}$, and $3 \mathrm{~b}^{\prime \prime}$ (solid black) in Fig. 8 divide to form two pairs of traces (Tr) as shown in Fig. 9, one pair of which supplies leaf 3a, the other leaf $3 b$. 


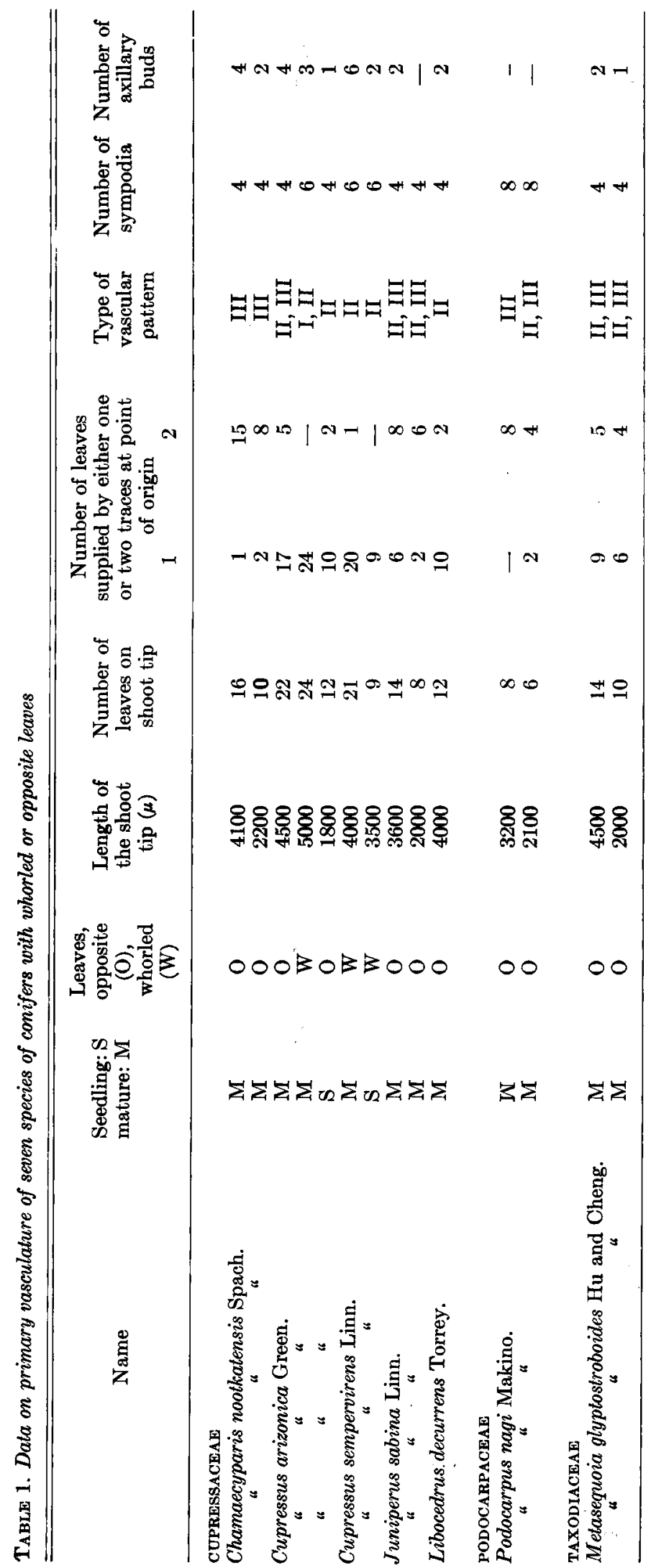


bryogeny (Buchholz, 1946), all speak for the derived nature of the family.

Florin (1951) in his study of the living and fossil conifer cones found features suggesting a change from the helical arrangement of appendages in Cordaitales to a decussate arrangement in later forms like Walchia and Lebachia. He interpreted the female cones of all the living conifers on this assumption of transformation of a helical arrangement of appendages to a decussate or whorled arrangement. If this interpretation is correct, there is reason to believe that this was the tendency in the vegetative appendages as well.

The above evidence suggests that the condition of opposite phyllotaxis is a derived characteristic rather than a basic, primitive one. The strong association between phyllotaxis and the vascular pattern, then, leads to the conclusion that the sympodial vascular pattern characteristic of conifers with helical phyllotaxis is primitive and basic, and that the irregular and reticulate patterns found in conifers with opposite and whorled leaves are derived.

This conclusion suggests that the leaf gap of conifers might not be homologous with that of the ferns since it contradicts the view of Barthelmess (1935)-i.e., that the reticulate system of some species with opposite phyllotaxis is primitive and the open system of the species with helical phyllotaxis is derived by reduction-the only basis for a Jeffreyan interpretation of stelar structure in these forms.

Since the origin of the vascular supply to each leaf as a single bundle is characteristic of the primitive, generalized, sympodial systems in conifers with helical phyllotaxis, it follows that this is also a primitive condition. If so, the view of Marsden and Bailey (1955) that the two-trace, unilacunar node is primitive in Pteropsida cannot, apply to the Coniferales. Our view supports a similar one expressed by Pant and Mehra (1964).

Stelar evolution in gymnosperms, including the question of the homology of the leaf gap in gymnosperms and ferns, will be dealt with in detail, drawing on important evidence from the fossil record, in part III of this study.

\section{LITERATURE CITED}

AASE, H. 1915. Vascular anatomy of the megasporophylls of conifers. Bot. Gaz. 60: 277-313.
Arnold, C. A. 1947. An introduction to paleobotany. McGraw-Hill, New York.

Barthelmess, A. 1935. Über den Zusammenhang zwischen Blattstellung und Stelenbau unterer besonderer Berücksichtigung der Koniferen. Bot. Arch. 37: 207-260.

BARY, A. DE. 1884. Comparative anatomy of the vegetative organs of the phanerogams and ferns. [English translation by F. O. Bower and D. H. Scott.] Oxford.

Buchноцz, J. T. 1946. Gymnosperms. Encyclopaedia Britannica.

Camefort, H. 1956. Etude de la structure du point végétatif et des variations phyllotaxiques chez quelques gymnospermes. Ann. Sci. Nat. Bot., Ser. XI, 17: 1-185.

Chamberlain, C. J. 1935. Gymnosperms, structure and evolution. Univ. Chicago Press, Chicago.

Dallimore, W., AND A. B. JACkson. 1954. A handbook of Coniferae including Ginkgoaceae. Edward Arnold Publishers, Ltd., London.

De Bary, A. 1884. Comparative anatomy of the vegetative organs of the phanerogams and ferns. [English translation by F. O. Bower and D. H. Scott.] Oxford.

Eames, A. J. 1913. The morphology of Agathis australis. Ann. Bot. 27: 1-38.

, and L. H. MacDaniels. 1947. An introduction to plant anatomy. 2nd ed. McGraw-Hill, New York.

Florin, R. 1938-1945. Die Koniferen des Oberkarbons und des Unteren Perms. Palaeontographica 85B: Pt. 1-8.

—— 1951. Evolution in Cordaites and conifers. Acta Hort. Berg. 15: 285-388.

GeYLER, H. T. 1867. Ueber den Gefässbündelverlauf in den Laubblattregionen der Coniferen. Jahrb. Wiss. Bot. 6: 55-208.

LaUbenfels, D. J. De. 1953. The external morphology of coniferous leaves. Phytomorphology 3: 1-20.

Marsden, M. P. F., AND I. W. Balley. 1955. A fourth type of nodal anatomy in dicotyledons, illustrated by Clerodendron trichotomum Thunb. J. Arnold Arbor. 36: 1-51.

Namboodiri, K. K., and C. B. Beck. 1968. A comparative study of the primary vascular system of conifers. I. Genera with helical phyllotaxis. Amer. J. Bot. 55: 447-457.

Pant, D. D., and B. Mehra. 1964. Nodal anatomy in retrospect. Phytomorphology 14: 384-387.

Sterling, C. 1949. Some features in the morphology of Metasequoia. Amer. J. Bot. 36: 461-471.

WIIDE, M. H. 1944. A new interpretation of coniferous cones: I. Podocarpaceae (Podocarpus). Ann. Bot. n.s. 8: $1-41$. 